\title{
Publisher Correction: Sub-stoichiometric 2D covalent organic frameworks from tri- and tetratopic linkers
}

\author{
Tanmay Banerjee (1) ${ }^{1}$, Frederik Haase (1) 1,2,5, Stefan Trenker ${ }^{2,3}$, Bishnu P. Biswal ${ }^{1}$, Gökcen Savasci (i) ${ }^{1,2}$, \\ Viola Duppel1', Igor Moudrakovski (10 1, Christian Ochsenfeld ${ }^{1,2,4}$ \& Bettina V. Lotsch (1) 1,2,3,4
}

Correction to: Nature Communications https://doi.org/10.1038/s41467-019-10574-6, published online 19 July 2019.

The original version of this Article contained an error in the legend of Fig. 5a, in which the blue data was incorrectly labelled 'PY ${ }_{2} \mathrm{~B}$ COF' rather than the correct ' $\mathrm{PT}_{2} \mathrm{~B}-\mathrm{COF}$ ' and the grey data was incorrectly labelled ' $\mathrm{PT}_{2} \mathrm{~B}-\mathrm{COF}$ ' rather than the correct ' $\mathrm{PY}{ }_{2} \mathrm{~B}-\mathrm{COF}$ '. This has been corrected in both the PDF and HTML versions of the Article.

Published online: 10 July 2019

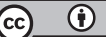

Open Access This article is licensed under a Creative Commons Attribution 4.0 International License, which permits use, sharing, adaptation, distribution and reproduction in any medium or format, as long as you give appropriate credit to the original author(s) and the source, provide a link to the Creative Commons license, and indicate if changes were made. The images or other third party material in this article are included in the article's Creative Commons license, unless indicated otherwise in a credit line to the material. If material is not included in the article's Creative Commons license and your intended use is not permitted by statutory regulation or exceeds the permitted use, you will need to obtain permission directly from the copyright holder. To view a copy of this license, visit http://creativecommons.org/licenses/by/4.0/.

(c) The Author(s) 2019

\footnotetext{
${ }^{1}$ Max Planck Institute for Solid State Research, Heisenbergstraße 1, 70569 Stuttgart, Germany. ${ }^{2}$ Department of Chemistry, University of Munich (LMU), Butenandtstraße 5-13, 81377 München, Germany. ${ }^{3}$ Cluster of Excellence e-conversion, Schellingstraße 4, 80799 München, Germany. ${ }^{4}$ Center for Nanoscience, Schellingstraße 4, 80799 München, Germany. ${ }^{5}$ Present address: Institute for Integrated Cell-Material Sciences (WPI-iCeMS), Kyoto University, Kyoto 606-8501, Japan. Correspondence and requests for materials should be addressed to T.B. (email: t.banerjee@fkf.mpg.de) or to B.V.L. (email: b.lotsch@fkf.mpg.de)
} 